\title{
Mycobacterium tuberculosis spoligotypes and drug susceptibility pattern of isolates from tuberculosis patients in peri-urban Kampala, Uganda
}

\author{
Benon B Asiimwe ${ }^{1,2}$, Solomon Ghebremichael 2,3, Gunilla Kallenius ${ }^{2,3}$, \\ Tuija Koivula ${ }^{3}$ and Moses L Joloba*1
}

\begin{abstract}
Address: ${ }^{1}$ Department of Medical Microbiology, Makerere University Medical School, P.O Box 7072, Kampala, Republic of Uganda, ${ }^{2}$ Department of Microbiology, Tumor and Cell Biology, Karolinska Institutet, SE-171 77, Stockholm, Sweden and ${ }^{3}$ Department of Bacteriology, Swedish Institute for Infectious Diseases Control, SE-171 82, Solna, Sweden

Email: Benon B Asiimwe - benon.asiimwe@ki.se; Solomon Ghebremichael - solomon.ghebremichael@smi.ki.se;

Gunilla Kallenius - gunilla.kallenius@smi.ki.se; Tuija Koivula - tuija.koivula@smi.ki.se; Moses L Joloba* - moses.joloba@case.edu

* Corresponding author
\end{abstract}

Published: 28 July 2008

BMC Infectious Diseases 2008, 8:101 doi:10.1186/147|-2334-8-101
Received: 4 February 2008

Accepted: 28 July 2008

This article is available from: http://www.biomedcentral.com/I47I-2334/8/10I

(c) 2008 Asiimwe et al; licensee BioMed Central Ltd.

This is an Open Access article distributed under the terms of the Creative Commons Attribution License (http://creativecommons.org/licenses/by/2.0), which permits unrestricted use, distribution, and reproduction in any medium, provided the original work is properly cited.

\begin{abstract}
Background: The poor peri-urban areas of developing countries with inadequate living conditions and a high prevalence of HIV infection have been implicated in the increase of tuberculosis (TB). Presence of different lineages of Mycobacterium tuberculosis has been described in different parts of the world. This study determined the predominant strain lineages that cause TB in Rubaga division, Kampala, Uganda, and the prevalence of resistance to key anti-tuberculosis drugs in this community.

Methods: This was a cross-sectional study of newly diagnosed sputum smear-positive patients aged $\geq 18$ years. A total of 344 isolates were genotyped by standard spoligotyping and the strains were compared with those in the international spoligotype database (SpolDB4). HIV testing and anti-tuberculosis drug susceptibility assays for isoniazid and rifampicin were performed and association with the most predominant spoligotypes determined.

Results: A total of 33 clusters were obtained from 57 spoligotype patterns. According to the SpoIDB4 database, 24 I (70\%) of the isolates were of the T2 family, while CASI-Kili (3.5\%), LAM9 (2.6\%), CASI-Delhi $(2.6 \%)$ were the other significant spoligotypes. Furthermore, a major spoligotype pattern of 17 (4.5\%) strains characterized by lack of spacers 15-17 and 19-43 was not identified in SpolDB4. A total of $92(26.7 \%)$ of the patients were HIV sero-positive, I76 (5I.2\%) sero-negative, while $76(22.1 \%)$ of the patients did not consent to HIV testing. Resistance to isoniazid was found in $8.1 \%$ of strains, while all $15(4.4 \%)$ strains resistant to rifampicin were multidrug resistant. Additionally, there was no association between any strain types in the sample with either drug resistance or HIV sero-status of the patients.
\end{abstract}

Conclusion: The TB epidemic in Kampala is localized, mainly caused by the T2 family of strains. Strain types were neither associated with drug resistance nor HIV sero-status. 


\section{Background}

Uganda is one of the countries with the highest burden of tuberculosis (TB) in Sub-Saharan Africa, with an estimated incidence of 559 cases per 100,000 per year and ranks $16^{\text {th }}$ among the 22 high-burden countries [1]. Kampala, the capital of Uganda, has an approximate population of 2 million (Nation Census, 2002) and accounts for $30 \%$ of the TB burden in the country (National Tuberculosis and Leprosy Control Programme, 2006). To date, there are very limited data available pertaining strains circulating in Uganda and the East African region as a whole [2-5]. Poor peri-urban areas of most developing countries where living conditions are unsatisfactory are usually affected by TB $[6,7]$. The presence of Human immunodeficiency virus (HIV) has caused an increase in Mycobacterium tuberculosis complex (MTC) infection [8] and rapid progression of the infection [9], and is also known to increase MTC transmission rates at the community level, further threatening the health and survival of HIV seronegative individuals as well [10].

Spoligotyping, one of the genotyping techniques, is a simple, rapid and cost-effective method that has been used widely to define predominant and a growing number of important clades worldwide [2,3,11-13]. The World spoligotyping Database, SpolDB4.0, describes an update on the global distribution of M. tuberculosis complex spoligotypes but shows little information about Uganda. A previous characterization of 234 MTC strains collected between 1995 and 1997 at the National Referral Hospital in Kampala grouped $67 \%$ of the isolates into two closely related spoligotype families [4] but provided neither an estimate of the burden of other strain lineages and associated HIV sero-status data nor the anti-tuberculosis susceptibility pattern of the isolates.

The present study has characterized isolates from a periurban patient population in Rubaga division, Kampala. We have assigned 244 of the 344 strains to the major clades in SpolDB4.0, and also investigated association between the predominant spoligotypes and HIV sero-status as well as anti-tuberculosis drug resistance in this community.

\section{Methods}

\section{Ethical considerations}

Institutional permission to conduct the study was obtained from the Faculty Research and Ethics Committee of Makerere University Medical School (institutional ethics board of the Medical School). Informed consent to participate in the study as well as permission to use isolates from samples provided were obtained from all enrolled participants.

\section{Study setting}

Patients were recruited from sputum smear positive residents in Rubaga attending four main TB clinics in the division. Sample processing, confirmatory microscopy and culture and susceptibility testing were performed at the National Tuberculosis and Reference Laboratory (NTRL); molecular assays were run at Makerere Medical School, and data analysis for spoligotyping was done at the Swedish Institute for Infectious Disease Control, Stockholm.

\section{Study design}

This was a cross sectional study in which all consecutive newly-presenting Ziehl-Neelsen (ZN) smear-positive patients between February and November 2006 aged 18 years and above were enrolled. The patient recruitment and sample collection process was done as described in our previous report [14]. Briefly, all patients underwent a standardized interview and three consecutive sputum samples (spot, early morning and spot) were taken from each patient. Only the sample with the highest ZN smear grade was further analyzed for each patient. Samples were stored at $4^{\circ} \mathrm{C}$ at the recruitment clinics, in any case for not more than 48 hours, until transported in a cold box to the NTRL for processing, confirmatory fluorescent microscopy and culture.

\section{Sputum sample processing}

Specimens (2.5-10 ml) were processed by the standard Nacetyl L-cystein (NALC)-NaOH method [15] and concentrated at $4000 \times g$ for 15 minutes. The sediment, irrespective of the original sample volume, was reconstituted to $2.5 \mathrm{ml}$ with phosphate buffer $\mathrm{pH} 6.8$, to make the inoculum for the smears and cultures.

\section{Culture and identification}

Two Lowenstein-Jensen slants, one containing $0.75 \%$ glycerol and the other containing $0.6 \%$ pyruvate, were inoculated with the sediment and incubated at $37^{\circ} \mathrm{C}$. Cultures were considered negative when no colonies were seen after 8 weeks incubation. Isolates were harvested, DNA extracted using a standardized protocol [16] and confirmed as MTC by an in-house PCR [17].

\section{Drug resistance assays}

Drug susceptibility testing (DST) was performed by the indirect proportion method on Lowenstein-Jensen media at the following final drug concentrations: rifampicin, 40 $\mu \mathrm{g} / \mathrm{ml}$ and isoniazid, $0.2 \mu \mathrm{g} / \mathrm{ml}$, as recommended elsewhere [18]. Multi-drug resistance (MDR) was defined in accordance with standard criteria of resistance to at least isoniazid and rifampicin. 


\section{Quality control for DST}

For all test panels, drug susceptible strain (H37Rv) and specific drug resistant strains (TMC 303 for isoniazid and TMC 331 for rifampicin) internal controls were included.

The NTRL successfully participates in two annual external proficiency testing programmes organized by Centers for Disease Control and Prevention (CDC) and the Supra national laboratory net work.

\section{Spoligotyping}

Standard spoligotyping [19] was done generally as described by Kamerbeek and colleagues using a commercially available kit (Isogen Bioscience BV, Maarssen, The Netherlands).

\section{HIV testing}

HIV-1 rapid testing was performed according to the Ministry of Health, Uganda, algorithm. Anticoagulated whole blood was immediately used for HIV rapid testing at the clinics of enrolment. Two rapid HIV tests, Unigold Recombinant HIV (Trinity Biotech, Wicklow, Ireland) and Determine HIV-1/2 (Abbott, Tokyo, Japan), were run sequentially. Samples were tested first with Abbot Determine and reported only when negative. Positive samples were confirmed with Unigold, while discordant results were resolved by a third rapid test kit, HIV-1/2 Stat-Pak (ChemBio, Medford, NY). All tests were performed and interpreted according to the manufacturers' instructions.

\section{Data analysis}

Spoligotypes were analysed by a BioNumerics software, version 5.0 (Applied Maths, Kortrijk, Belgium) as character types. The obtained signatures were compared in binary format with the international spoligotyping database of the Pasteur Institute of Guadeloupe. The SpolDB4 database [20] (an online version is available on http:// www.pasteur-guadeloupe.fr:8081/SITVITDemo) provides information on the spoligotype international type (SIT) distributions of $M$. tuberculosis spoligotypes worldwide. Labels for major phylogenetic clades were assigned according to signatures provided in SpolDB4. Statistical associations between strain types, drug susceptibility data and HIV sero-status were generated by Stata 8.0 using the Pearson's chi-square test. Odds ratios were estimated at $95 \%$ confidence intervals, and a $P$ value of $<0.05$ was considered evidence of a significant difference.

\section{Results}

\section{Study population and samples analyzed}

Between February and November 2006, 2639 TB suspects from Rubaga division, Kampala, were screened at 4 division TB clinics. The population of Rubaga division is mainly low to middle income, and the clinics chosen are the subsidized mission founded hospitals at which a majority of the residents seek medical care. Only 386 of these suspects were sputum smear positive and enrolled. Extra samples from randomly selected patients were taken for internal quality control as generally described in our previous report [14]. The demographic information of the patients shows that $163(47.4 \%)$ of the isolates were from female patients while 181 (52.6\%) were male. The sample median age was 32 with a range of 18 to 62 years. The median age among female subjects was 30 (SD 8.3) with a range of 18 to 60 years while that of the males was 34 (SD 8.6) with a range of 18-62 years. Stratification according to age showed that $267(77.7 \%)$ of the patients were between 18 and 39 years old while 75 (22\%) were between 40 and 60 years. Only $1(0.3 \%)$ patient was over 60 years of age.

\section{Spoligotypes}

To determine the strain lineages present in the sample, the 344 isolates were spoligotyped and binary outcomes compared with those existing in SpolDB4 so as to assign spoligotype international type (SIT) designations. A total of 320 isolates, or $93 \%$ of our sample, were grouped into 33 clusters ( 2 to 49 isolates per cluster), while the remaining $24(7 \%)$ of the strains did not cluster. Of these 24 strains that did not cluster, 21 did not exist in the SpolDB4.0 data base, hence represented the true orphans in the study sample. The remaining 3 of the unclustered isolates included one $M$. bovis strain and were all present in SpolDB4 with labels SIT 34 (S), SIT 61 (LAM10-CAM), and SIT 482 (BOV1) for the M. bovis strain.

Among the 33 clusters, seven included more than ten isolates each and were defined as major spoligotypes, while minor spoligotypes, on the other hand, were defined as spoligotype international types (SITs) that contained two to ten isolates per cluster (Figure 1). Analysis of the frequency of the spoligotypes in our study with SpolDB4.0 allowed differentiation between ubiquitous types (SIT 1, SIT 4, SIT 21, SIT 26, SIT 42, SIT 52, SIT 59, SIT 78, SIT 356, and SIT 288) and those believed to be endemic in Uganda (SIT 125, SIT 128, SIT 135, and SIT 590). Furthermore, up to 14 clusters ranging from two to seventeen isolates per cluster formed a total of 100 strains and were not yet defined in SpolDB4.0. These were labeled UGA1 (17 isolates) to UGA14 ( 2 isolates) (Figure 1 ). Seventy percent (241/344) of the isolates lacked hybridization to either spacer 40 or both 40 and 43 , and these were characteristic of strains that were previously classified as $M$. africanum genotypes Uganda II and I respectively [21]. Most (227/ 241) of the Uganda genotype strains formed 16 clusters (ranging 5 to 49 isolates) with 80 strains being genotype I while 147 were genotype II (Figure 1). Only 14 Uganda genotype strains did not cluster. 


\begin{tabular}{|c|c|c|c|c|}
\hline Order & $\mathrm{SIT}^{\mathrm{a}}$ & $\mathrm{N}^{\mathrm{b}}(\%)$ & Spoligotype Pattern ${ }^{\mathrm{c}}$ & Label $^{\mathrm{d}}$ \\
\hline 1 & 1 & $04(1.2)$ & & Beijing \\
\hline 2 & 128 & 49 (14.2) & & $\mathrm{T} 2$ \\
\hline 3 & 135 & $38(11.0)$ & & T2-Uganda \\
\hline 4 & 52 & $26(7.6)$ & & $\mathrm{T} 2$ \\
\hline 5 & UGA1 & $17(4.5)$ & & $\mathrm{ND}$ \\
\hline 6 & 590 & $15(4.4)$ & & $\mathrm{T} 2$ \\
\hline 7 & 21 & $12(3.5)$ & & CAS1_KILI \\
\hline 8 & 125 & $11(3.2)$ & & $\mathrm{T} 2$ \\
\hline 9 & UGA2 & $10(2.9)$ & & $\mathrm{T} 2$ \\
\hline 10 & 42 & $09(2.6)$ & & LAM9 \\
\hline 11 & 26 & $09(2.6)$ & & CAS1_DELHI \\
\hline 12 & UGA3 & $09(2.6)$ & & $\mathrm{T} 2$ \\
\hline 13 & 78 & 09 (2.6) & & T1-T2 \\
\hline 14 & UGA4 & $09(2.6)$ & & $\mathrm{T} 2$ \\
\hline 15 & 1332 & $09(2.6)$ & & $\mathrm{T} 2$ \\
\hline 16 & UGA5 & $09(2.6)$ & & $\mathrm{T} 2$ \\
\hline 17 & UGA6 & $08(2.3)$ & & $\mathrm{T} 2$ \\
\hline 18 & UGA7 & $07(2.0)$ & & $\mathrm{T} 2$ \\
\hline 19 & UGA8 & $07(2.0)$ & & $\mathrm{T} 2$ \\
\hline 20 & 4 & $06(1.7)$ & & LAM3/S \\
\hline 21 & 356 & $06(1.7)$ & & CAS \\
\hline 22 & UGA9 & $06(1.7)$ & & $\mathrm{T} 2$ \\
\hline 23 & 59 & $05(1.5)$ & & LAM11-ZWE \\
\hline 24 & UGA10 & $05(1.5)$ & & $\mathrm{T} 2$ \\
\hline 25 & UGA11 & $04(1.2)$ & & ND \\
\hline 26 & UGA12 & $04(1.2)$ & & ND \\
\hline 27 & 126 & $03(0.9)$ & & EAI5 \\
\hline 28 & 358 & $03(0.9)$ & & $\mathrm{T} 1$ \\
\hline 29 & UGA13 & $03(0.9)$ & & ND \\
\hline 30 & 512 & $02(0.6)$ & & $\mathrm{H} 3$ \\
\hline 31 & 64 & $02(0.6)$ & & LAM6 \\
\hline 32 & 288 & $02(0.6)$ & & CAS2 \\
\hline 33 & UGA14 & $02(0.6)$ & & ND \\
\hline
\end{tabular}

Figure I

Spoligotype pattern of clustered M. tuberculosis strains in the study. ${ }^{\text {AAs }}$ identified in SpolDB4.0; SIT, spoligotype international type; $\mathrm{N}^{\mathrm{b}}$, number of isolates (as a percentage of total $M$. tuberculosis strains in the study); cfilled boxes represent positive hybridization while empty boxes represent absence of spacers; dlabel defining the lineage/sub lineage; ND, not yet determined in SpoIDB4.0.

Overall, 4 Beijing strains (SIT 1) were identified, making $1.2 \%$ of the sample. The six major shared spoligotypes in our sample were SIT 128 or T2 with 49 isolates, SIT 135 (T2-Uganda) with 38 isolates, SIT 52 (T2) with 26 isolates, SIT 590 (T2) with 15 isolates, SIT 21 (CAS1-Kili) with 12 isolates and SIT 125 (T2) with 11 isolates. Additionally, one other major cluster of 17 isolates with a characteristic lack of hybridization to spacers 15-17 and 1943 is not yet defined in SpolDB4.0 and was labeled UGA 1 (figure 1).

\section{HIV sero-status}

In the current sample, 92 patients $(26.7 \%)$ were HIV seropositive, 176 (51.2\%) sero-negative, while $76(22.1 \%)$ did not consent to HIV testing hence their status unknown. There was no significant difference $(P=0.116)$ in sero-status between female and male patients in the sample. An analysis of the predominant spoligotypes in HIV sero-positive and sero-negative patients showed that $53 / 92(57.6 \%)$ of sero-positive individuals carried strains of the T2 family, while only $6.5 \%$ carried the CAS strains, $3.3 \% \mathrm{LAM} 3 / \mathrm{S}$, and $4.3 \%$ carried unique strains. Further- more, $138 / 176$ (78.4\%) of the HIV sero-negative individuals and $50 / 76(65.8 \%)$ of those who did not consent carried the T2 family of strains. The other patients carried either minor spoligotypes or those not yet defined in SpolDB4.

\section{Drug susceptibility patterns}

Susceptibility testing results for the two key anti-tuberculosis drugs (isoniazid and rifampicin) showed that resistance to isoniazid was $28 / 344(8.1 \%)$, that to rifampicin was $15 / 344(4.4 \%)$, and all the rifampicin resistant isolates were also MDR, being defined as resistance to both isoniazid and rifampicin. 13 strains, including 1 Beijing genotype, were monoresistant to isoniazid. Five patients were recruited with recurrent $\mathrm{TB}$, but all the isolates were susceptible. There was no relationship $(\mathrm{p}=0.80)$ between MDR and HIV sero-positivity. A summary of patient demographic characteristics and associated drug susceptibility pattern is shown in Table 1.

Regarding cluster analysis in drug resistant isolates, SIT 52 (T2) had four of the 15 MDR isolates; SIT 128 (T2) three 
Table I: Demographic characteristics and drug susceptibility pattern of isolates in the study

\begin{tabular}{|c|c|c|c|c|c|c|}
\hline \multirow[b]{2}{*}{$\begin{array}{l}\text { Demographic } \\
\text { characteristics }\end{array}$} & & \multirow[b]{2}{*}{ Total } & \multicolumn{4}{|c|}{ Drug susceptibility pattern } \\
\hline & & & Susceptible & $\begin{array}{l}\text { Resistant to } \\
\text { Isoniazida }^{\mathbf{a}}\end{array}$ & $\begin{array}{l}\text { Resistant to } \\
\text { Rifampicin }\end{array}$ & MDR \\
\hline Total no. of strains & & 334 & 316 & 13 & 0 & 15 \\
\hline \multirow[t]{2}{*}{ Sex } & Women & 163 & 153 & 7 & 0 & 3 \\
\hline & Men & $|8|$ & 163 & 6 & 0 & 12 \\
\hline \multirow[t]{2}{*}{ History of TB } & New cases & 339 & 311 & 13 & 0 & 15 \\
\hline & Retreatment & 5 & 5 & 0 & 0 & 0 \\
\hline \multirow{3}{*}{ HIV status } & Positive & 92 & 84 & 5 & 0 & 3 \\
\hline & Negative & 176 & 164 & 4 & 0 & 8 \\
\hline & Unknown & 76 & 68 & 4 & 0 & 4 \\
\hline \multirow[t]{3}{*}{ Age group (years) } & $18-39$ & 267 & 249 & 7 & 0 & 11 \\
\hline & $40-60$ & 76 & 66 & 6 & 0 & 4 \\
\hline & $>60$ & I & 1 & 0 & 0 & 0 \\
\hline
\end{tabular}

aResistance to isoniazid other than MDR; bresistance to rifampicin other than MDR; MDR = multidrug resistant strains

MDR isolates, while SIT 135 (T2-Uganda) had two MDR isolates. The other $6 \mathrm{MDR}$ isolates were distributed as follows: one LAM9 (SIT 42), one UGA7 (T2), one UGA18 and three unique (T2) isolates. Although strains of the T2 family accounted for 13 of the fifteen MDR strains in the sample, there was no statistical relationship $(p=0.25)$ between this strain type and MDR. The relationship between the different spoligotypes and resistance to rifampicin, isoniazid or both is summarized in Table 2.

\section{Discussion}

Characterization of prevailing M. tuberculosis lineages and clones focusing on different geographical levels such as continents, countries, regions or cities is important for locating the origin, evolution and spreading dynamics of a particular M. tuberculosis clone, which is often difficult to be identified by traditional epidemiological investigations alone. Like most of sub-Saharan Africa, Uganda has a high prevalence of TB infection with peri-urban communities of Kampala recording higher rates than those in the rest of the country [22]. In this region where $\mathrm{TB}$ is endemic, it is critical to identify predominant strain types in order to study transmission patterns within communities and to understand the epidemiology of the disease in the country as a whole. This report presents the largest amount of molecular epidemiological data on M. tuberculosis isolates from Uganda to date. It is also the first systematic community based study conducted to assess strain diversity, associated HIV sero-status and anti-tuberculosis drug resistance of M. tuberculosis complex in a peri-urban population of Uganda.

Our findings on the predominance of the T2 family of strains in Kampala compare well with previous data from the study at Mulago hospital, Kampala, in which $67 \%$ of the isolates were identified as lacking hybridization to either spacer 40 or both 40 and 43 [4,21]. Else where in East Africa, a previous study in Kenya found only eight $(11 \%)$ of 73 isolates to be of the T2 family and its variants, while in northern Tanzania four (3\%) of 130 strains were T2-Uganda, frequencies much lower than $70 \%$ observed in our sample [3]. It is therefore plausible that the TB epidemic in Kampala is local and well established, and that this strain is well adapted to transmit in the local popula-

Table 2: Association of drug resistance to isoniazid and rifampicin with spoligotypes

\begin{tabular}{|c|c|c|c|c|c|}
\hline \multirow[b]{3}{*}{ Characteristic } & \multicolumn{5}{|c|}{ No. (\%) strains } \\
\hline & \multicolumn{4}{|c|}{ Spoligotypes } & \multirow{2}{*}{$\begin{array}{c}\text { All } \\
\text { spoligotypes }\end{array}$} \\
\hline & LAM9 & T2 & Beijing & Others & \\
\hline Sensitivity to two key drugs ${ }^{a}$ & $6(1.7)$ & $221(64.2)$ & $3(0.9)$ & $86(25)$ & $316(91.8)$ \\
\hline Multidrug resistance & $\mathrm{I}(0.3)$ & $13(3.8)$ & $0(0)$ & I $(0.3)$ & $15(4.4)$ \\
\hline Isoniazid resistance ${ }^{b}$ & $2(0.6)$ & $7(2.0)$ & $\mathrm{I}(0.3)$ & $3(0.9)$ & $13(3.8)$ \\
\hline Rifampicin resistance ${ }^{b}$ & $0(0)$ & $0(0)$ & $0(0)$ & $0(0)$ & $0(0)$ \\
\hline Total & 9 & 241 & 4 & 90 & 344 \\
\hline
\end{tabular}

alsoniazid and Rifampicin; bother than MDR 
tion. Similar trends have been observed in other studies where local genotypes tend to form a greater proportion of the circulating strains. Cases in point are Guinea Bissau where $199(51 \%)$ of 229 isolates belonged to the Guinea Bissau family [23]; Cameroon where 193 (46.7\%) of 413 M. tuberculosis isolates belonged to the Cameroon family, LAM10-CAM [24]; Harare, Zimbabwe where 68/214 $(31.8 \%)$ isolates in one study and $116 / 246(47.2 \%)$ in another were LAM-ZWE variants $[25,26]$ and in Zambia where $74 / 114(65 \%)$ isolates were also of the LAM-ZWE family [26]. These are in further agreement with recent findings where it was noted that different strains of $M$. tuberculosis have adapted to specific human populations, and that such local strains are more likely to transmit compared to others $[27,28]$.

Other significant spoligotypes in our study were CAS1-Kili (3.5\%), LAM9 (2.6\%), CAS1-Delhi (2.6\%), LAM3/S $(1.7 \%)$, CAS1 $(1.7 \%)$, and LAM11-ZWE (1.5\%). In comparison to other studies in the region, the CAS, LAM and EAI families were reported at $37 \%, 22 \%$ and $17 \%$ respectively of a total of 147 isolates in a study in Dar es Salaam, Tanzania [2]; while in northern Tanzania, the most predominant families were CAS-Kili (30\%), LAM11-ZWE (14.6\%), EAI (6.2\%), Beijing (5.4\%), and CAS1-Delhi, T1 and LAM9 at 3.8\% [5]. In Kenya, on the other hand, $35.6 \%$ of 73 isolates were of the CAS family, while $11 \%$ were LAM [3]. These studies show more success of the CAS, LAM and EAI families in the neighboring East African countries, while in Central Uganda, the T2 family of strains predominates.

A comparison of the prevalence of the Beijing family of strains, highly prevalent in many Asian locations [13], shows that in East Africa, Tanzania has reported 14 cases $[2,5]$, Kenya six [3], while in a recent study of mycobacteria causing human cervical lymphadenitis in pastoral communities in the Karamoja region of Uganda, three isolates with the Beijing spoligotype were identified from 34 biopsies [29], but the susceptibility pattern and associated HIV sero-status of the individuals is not known. In this study, to the best of our knowledge, we report the first four M. tuberculosis Beijing strains in Uganda with known anti-tuberculosis drug susceptibility pattern to date, with none of the four strains being MDR. Our results further show that the Beijing family at $1.2 \%$ is not common. This result differs from that seen in a study in Kenya in which two of the six Beijing strains in the collection were MDR [3]. In Malawi, 44/1,029 (4.3\%) of strains in one study were Beijing and susceptible [30]; in the Dar es Salaam study, the susceptibility pattern of the seven Beijing isolates was not determined [2], while more recently in northern Tanzania, 5.4\% of 130 isolates were Beijing and all susceptible. Generally, the trend and susceptibility pattern of the Beijing genotype in sub-Saharan Africa has been described to be one of three: epidemic and associated with drug resistance (high level in South Africa); epidemic but drug sensitive (Malawi); and very low level or absent (parts of Africa) [31]. Our data suggest that the Beijing strains in Kampala are of the low level and susceptibility pattern.

The emergence of drug resistance in the treatment of $\mathrm{TB}$ has complicated its management. In the developing countries, lack of resources hinder regular drug resistance surveys, hence the magnitude of this problem remains largely unknown. The last national anti-tuberculosis drug resistance survey in Uganda (1996-1997) on 586 patients [32] indicated that primary resistance to isoniazid was $6.7 \%$, that to rifampicin $0.8 \%$, while MDR was $0.5 \%$. In neighboring Rwanda, the most recent survey results [33] show that of 616 strains from new cases, $6.2 \%$ were resistant to isoniazid, $3.9 \%$ to rifampicin and $3.9 \%$ were multidrugresistant TB. In northern Tanzania, a study of 111 isolates showed that $9.9 \%$ were resistant to isoniazid, $2.7 \%$ to rifampicin, with $2.7 \%$ being MDR [5]. Our result for resistance to isoniazid at $8.1 \%$ is comparable to that in northern Tanzania, while that to rifampicin $(4.4 \%)$ is comparable to the Rwanda findings.

Regarding cluster analysis, although the $\mathrm{T} 2$ family of strains accounted for 13/15 MDR strains, there was no statistical evidence $(p=0.25)$ to suggest that it might be the driving force of anti-tuberculosis drug resistance in this community. Additionally, as observed in northern Tanzania [5], our results show that HIV sero-status could not be identified with a particular spoligopattern. Furthermore, import of strains from Asia (CAS1-Kili, 3.5\%; CAS1-Delhi, 2.6\%; CAS1, 1.7\%; and CAS2, 0.6\%) has not had a major impact on the $M$. tuberculosis population in Kampala. However, together with the single $M$. bovis seen in our sample, there is clearly a diverse set of Mycobacterium tuberculosis complex strains circulating in Kampala, although $\mathrm{T} 2$ strains are predominant.

\section{Conclusion}

This study provides an insight into the M. tuberculosis strains circulating in Kampala. We have shown that the T2 family is likely to be responsible for the TB epidemic in this region, and that import of new strains has not had a significant bearing on the burden of disease in Rubaga division. Additionally, strain types in our sample were neither associated with drug resistance nor HIV sero-status.

\section{Competing interests}

The authors declare that they have no competing interests. 


\section{Authors' contributions}

BBA participated in the design and conduct of the study, acquisition of samples and demographic data, culture and isolation of mycobacteria, molecular assays, data analysis and drafting of manuscript; SG participated in data analysis and critical revision of manuscript; GK participated in the conception and design of the study, general supervision of the research in Sweden, and critical revision of the manuscript; TK participated in general supervision of the research in Sweden and critical revision of the manuscript; MLJ participated in the conception and design of the study, general supervision of the research in Uganda, and critical revision of the manuscript. All authors read and approved the final version of the manuscript.

\section{Acknowledgements}

This study was funded by Sida/SAREC through Makerere University and Karolinska Institute Research and Training (KIRT) collaboration. GK was also supported by a grant from the Swedish Heart Lung Foundation. We thank the staff of the National Tuberculosis Reference Laboratory, Uganda, who assisted in sample processing, culture and drug susceptibility testing; and Dr. Lukoye of the National TB and Leprosy Programme, Rubaga division, for orientation and clinic supervision during the study period.

\section{References}

I. WHO: Global tuberculosis control: surveillance, planning, financing. WHO report 2007. WHO/HTM/TB/2007.376. Geneva, World health Organisation; 2007.

2. Eldholm V, Matee M, Mfinanga SG, Heun M, Dahle UR: A first insight into the genetic diversity of Mycobacterium tuberculosis in Dar es Salaam, Tanzania, assessed by spoligotyping. BMC Microbiol 2006, 6:76.

3. Githui WA, Jordaan AM, Juma ES, Kinyanjui P, Karimi FG, Kimwomi J, Meme H, Mumbi P, Streicher EM, Warren R, Meme H, Mumbi P, Streicher EM, Warren R, van Helden PD, Victor TC: Identification of MDR-TB Beijing/W and other Mycobacterium tuberculosis genotypes in Nairobi, Kenya. Int J Tuberc Lung Dis 2004, 8(3):352-360.

4. Niemann S, Rusch-Gerdes S, Joloba ML, Whalen CC, Guwatudde D, Ellner J], Eisenach K, Fumokong N, Johnson JL, Aisu T, Mugerwa RD, Okwera A, Schwander SK: Mycobacterium africanum subtype II is associated with two distinct genotypes and is a major cause of human tuberculosis in Kampala, Uganda. J Clin Microbiol 2002, 40(9):3398-3405.

5. Kibiki GS, Mulder B, Dolmans WM, de Beer JL, Boeree M, Sam N, van Soolingen $D$, Sola $C$, Zanden AG van der: M. tuberculosis genotypic diversity and drug susceptibility pattern in HIVinfected and non-HIV-infected patients in northern Tanzania. BMC Microbiol 2007, 7:51.

6. Tupasi TE, Radhakrishna S, Quelapio MI, Villa ML, Pascual ML, Rivera $A B$, Sarmiento A, Co VM, Sarol JN, Beltran G, Legaspi JD, Mangubat NV, Reyes AC, Solon M, Solon FS, Burton L, Mantala MJ: Tuberculosis in the urban poor settlements in the Philippines. Int J Tuberc Lung Dis 2000, 4(I):4-II.

7. Banerjee A, Harries AD, Salaniponi FM: Differences in tuberculosis incidence rates in township and in rural populations in Ntcheu District, Malawi. Trans R Soc Trop Med Hyg 1999, 93(4):392-393.

8. Bucher HC, Griffith LE, Guyatt GH, Sudre P, Naef M, Sendi P, Battegay $M$ : Isoniazid prophylaxis for tuberculosis in HIV infection: a meta-analysis of randomized controlled trials. Aids 1999, I3(4):50I-507.

9. Daley CL, Small PM, Schecter GF, Schoolnik GK, McAdam RA, Jacobs WR Jr, Hopewell PC: An outbreak of tuberculosis with accelerated progression among persons infected with the human immunodeficiency virus. An analysis using restriction-fragment-length polymorphisms. N Engl J Med 1992, 326(4):23|-235.
10. Odhiambo JA, Borgdorff MW, Kiambih FM, Kibuga DK, Kwamanga DO, Ng'ang'a L, Agwanda R, Kalisvaart NA, Misljenovic O, Nagelkerke NJ, Bosman M: Tuberculosis and the HIV epidemic: increasing annual risk of tuberculous infection in Kenya, 1986-1 996. Am J Public Health 1999, 89(7): 1078-1082.

II. Diguimbaye C, Hilty M, Ngandolo R, Mahamat HH, Pfyffer GE, Baggi F, Tanner M, Schelling E, Zinsstag J: Molecular characterization and drug resistance testing of Mycobacterium tuberculosis isolates from Chad. J Clin Microbiol 2006, 44(4): I575-I577.

12. Hasan Z, Tanveer M, Kanji A, Hasan Q, Ghebremichael S, Hasan R: Spoligotyping of Mycobacterium tuberculosis isolates from Pakistan reveals predominance of Central Asian Strain I and Beijing isolates. J Clin Microbiol 2006, 44(5): $1763-1768$.

13. van Soolingen D, Qian L, de Haas PE, Douglas JT, Traore H, Portaels F, Qing HZ, Enkhsaikan D, Nymadawa P, van Embden JD: Predominance of a single genotype of Mycobacterium tuberculosis in countries of east Asia. J Clin Microbiol 1995, 33( ( 2):3234-3238.

14. Asiimwe BB, Koivula T, Kallenius G, Huard RC, Ghebremichael S, Asiimwe J, Joloba ML: Mycobacterium tuberculosis Uganda genotype is the predominant cause of tuberculosis in Kampala, Uganda. Int J Tuberc Lung Dis 2008, I 2(4):386-391.

15. Kent PT, Kubica GP: Public health mycobacteriology: $\mathbf{A}$ guide for the level III laboratory. U. S. department of Health and Human Services. Centres for Disease Control, Atlanta, Ga. 1985.

16. van Embden JDA, Cave D, Crawford JT, Dale JW, Eisenach KD, Gicquel B, Hermans P, Martin C, McAdam R, Shinnick TM, Small PM: Strain identification of Mycobacterium tuberculosis by DNA fingerprinting: recommendations for a standardized methodology. J Clin Microbiol 1993, 3 I:406-409.

17. Muhumuza J, Asiimwe BB, Kayes S, Mugyenyi R, Whalen C, Mugerwa $\mathrm{RD}$, Boom $\mathrm{H}$, Eisenach KD, Joloba ML: Introduction of an inhouse PCR for routine identification of $M$. tuberculosis in a low-income country. Int J Tuberc Lung Dis 2006, I0(II): I 262-1267.

18. Aziz MA, Laszlo A, Raviglione M, Rieder H, Espinal M, Wright A, eds: Guidelines for surveillance of drug resistance in tuberculosis. 2nd ed. World Health Organization 2003. Document WHOI CDS/CSR/RMD/2003.3.

19. Kamerbeek J, Schouls L, Kolk A, van Agterveld M, van Soolingen $D$, Kuijper S, Bunschoten A, Molhuizen H, Shaw R, Goyal M, van Embden J: Simultaneous detection and strain differentiation of Mycobacterium tuberculosis for diagnosis and epidemiology. J Clin Microbiol 1997, 35(4):907-914.

20. Brudey K, Driscoll JR, Rigouts L, Prodinger WM, Gori A, AI-Hajoj SA, Allix C, Aristimuno L, Arora J, Baumanis V, Binder L, Cafrune P, Cataldi A, Cheong S, Diel R, Ellermeier C, Evans JT, Fauville-Dufaux M, Ferdinand S, Garcia de Viedma D, Garzelli C, Gazzola L, Gomes HM, Guttierez MC, Hawkey PM, van Helden PD, Kadival GV, Kreiswirth BN, Kremer K, Kubin M, et al.: Mycobacterium tuberculosis complex genetic diversity: mining the fourth international spoligotyping database (SpoIDB4) for classification, population genetics and epidemiology. BMC Microbiol 2006, 6:23.

21. Niemann S, Kubica T, Bange FC, Adjei O, Browne EN, Chinbuah MA, Diel R, Gyapong J, Horstmann RD, Joloba ML, Meyer CG, Mugerwa RD, Okwera A, Osei I, Owusu-Darbo E, Schwander SK, Rusch-Gerdes S: The species Mycobacterium africanum in the light of new molecular markers. J Clin Microbiol 2004, 42(9):3958-3962.

22. Guwatudde D, Zalwango S, Kamya MR, Debanne SM, Diaz MI, Okwera A, Mugerwa RD, King C, Whalen CC: Burden of tuberculosis in Kampala, Uganda. Bull World Health Organ 2003, 8I(II):799-805.

23. Kallenius G, Koivula T, Ghebremichael S, Hoffner SE, Norberg R, Svensson E, Dias F, Marklund BI, Svenson SB: Evolution and clonal traits of Mycobacterium tuberculosis complex in Guinea-Bissau. J Clin Microbiol I 999, 37( I 2):3872-3878.

24. Niobe-Eyangoh SN, Kuaban C, Sorlin P, Thonnon J, Vincent V, Gutierrez MC: Molecular characteristics of strains of the cameroon family, the major group of Mycobacterium tuberculosis in a country with a high prevalence of tuberculosis. J Clin Microbiol 2004, 42(II):5029-5035.

25. Easterbrook PJ, Gibson A, Murad S, Lamprecht D, Ives N, Ferguson A, Lowe O, Mason P, Ndudzo A, Taziwa A, Makombe R, Mbengeranwa L, Sola C, Rastogi N, Drobniewski F: High rates of clustering of strains causing tuberculosis in Harare, Zimbabwe: a 
molecular epidemiological study. J Clin Microbiol 2004, 42(10):4536-4544.

26. Chihota V, Apers L, Mungofa S, Kasongo W, Nyoni IM, Tembwe R, Mbulo G, Tembo M, Streicher EM, Spuy GD van der, Victor TC, van Helden P, Warren RM: Predominance of a single genotype of Mycobacterium tuberculosis in regions of Southern Africa. Int J Tuberc Lung Dis 2007, I I(3):3 I I-3 I8.

27. Gagneux S, DeRiemer K, Van T, Kato-Maeda M, de Jong BC, Narayanan S, Nicol M, Niemann S, Kremer K, Gutierrez MC, Hilty M, Hopewell PC, Small PM: Variable host-pathogen compatibility in Mycobacterium tuberculosis. Proc Natl Acad Sci USA 2006, I 03(8):2869-2873.

28. Gagneux S, Small PM: Global phylogeography of Mycobacterium tuberculosis and implications for tuberculosis product development. Lancet Infect Dis 2007, 7(5):328-337.

29. Oloya J, Opuda-Asibo J, Kazwala R, Demelash AB, Skjerve E, Lund A, Johansen TB, Djonne B: Mycobacteria causing human cervical lymphadenitis in pastoral communities in the Karamoja region of Uganda. Epidemiol Infect 2007, 136(5):636-643.

30. Glynn JR, Crampin AC, Traore H, Yates MD, Mwaungulu FD, Ngwira BM, Chaguluka SD, Mwafulirwa DT, Floyd S, Murphy C, Drobniewski FA, Fine PE: Mycobacterium tuberculosis Beijing genotype, northern Malawi. Emerg Infect Dis 2005, I I (I): I50-I53.

31. Beijing/W genotype Mycobacterium tuberculosis and drug resistance. European concerted action on new generation genetic markers and techniques for the epidemiology and control of tuberculosis. Emerg Infect Dis 2006, I 2(5):736-743.

32. Bretzel G, Aziz M, Wendl-Richter U, Adatu F, Aisu T, van Wijnen A, Sticht-Groh V: Anti-tuberculosis drug resistance surveillance in Uganda 1996-1997. Int J Tuberc Lung Dis 1999, 3(9):810-815.

33. Umubyeyi AN, Vandebriel G, Gasana M, Basinga P, Zawadi JP, Gatabazi J, Pauwels P, Nzabintwali F, Nyiramasarabwe L, Fissette K, Rigouts L, Struelens MJ, Portaels F: Results of a national survey on drug resistance among pulmonary tuberculosis patients in Rwanda. Int J Tuberc Lung Dis 2007, I I (2): 189-194.

\section{Pre-publication history}

The pre-publication history for this paper can be accessed here:

http://www.biomedcentral.com/1471-2334/8/101/pre pub

Publish with Bio Med Central and every scientist can read your work free of charge

"BioMed Central will be the most significant development for disseminating the results of biomedical research in our lifetime. "

Sir Paul Nurse, Cancer Research UK

Your research papers will be:

- available free of charge to the entire biomedical community

- peer reviewed and published immediately upon acceptance

- cited in PubMed and archived on PubMed Central

- yours - you keep the copyright

Submit your manuscript here:

http://www.biomedcentral.com/info/publishing_adv.asp
BioMedcentral 